CZASOPISMO INŻYNIERII LA¿OWEJ, ŚRODOWISKA I ARCHITEKTURY JOURNAL OF CIVIL ENGINEERING, ENVIRONMENT AND ARCHITECTURE JCEEA, t. XXXIII, z. 63 (1/II/16), styczeń-marzec 2016, s. 25-32

\author{
Paweł POPIELSKI ${ }^{1}$ \\ Błażej SMOLIŃSKI ${ }^{2}$ \\ Adam KASPRZAK ${ }^{3}$
}

\title{
OCENA STANU OBIEKTÓW HYDROTECHNICZNYCH NA PODSTAWIE WYNIKÓW INTERDYSCYPLINARNYCH PROGRAMÓW BADAŃ I SYMULACJI NUMERYCZNYCH
}

\begin{abstract}
Obiekty hydrotechniczne pełnią istotną rolę w funkcjonowaniu społeczeństwa i gospodarki krajowej. Oprócz funkcji przeciwpowodziowych, pełnią funkcje retencyjne i rekreacyjne. Często umożliwiają także produkcję energii elektrycznej, tym cenniejszej, że ekologicznie „,czystej”. Dbanie o prawidłowy stan techniczny obiektów hydrotechnicznych jest niezmiernie istotne z punktu widzenia bezpieczeństwa ludności oraz wielu innych aspektów techniczno-ekonomicznych. Należy również wspomnieć, że obowiązek wykonywania regularnych ocen stanu technicznego i przeglądów jest zapisany w polskim prawodawstwie. Stąd tak ważną kwestią jest kompleksowa analiza tego typu konstrukcji pod kątem naprężeń, odkształceń, zjawisk filtracyjnych oraz stateczności. Konieczne jest przy tym uwzględnienie obciążeń oraz współpracy obiektu z podłożem. W artykule zaprezentowano szerokie możliwości zastosowania analiz numerycznych w ocenie stanu technicznego konstrukcji hydrotechnicznych. W pracy skupiono się na nowoczesnych metodach pozyskiwania danych niezbędnych do generacji modeli obliczeniowych, kładąc szczególny nacisk na metody nieniszczące. W artykule omówiono metody geofizyczne oraz możliwość wykorzystania skaningu laserowego. Przedstawiono podstawowe założenia teoretyczne metody elementów skończonych (MES) oraz zaprezentowano sposoby jej implementacji w analizie konstrukcji hydrotechnicznych, zarówno ziemnych jak i betonowych. W pracy zamieszczono kilka wybranych przykładów modeli numerycznych 2D i 3D różnych typów obiektów. Poruszono zagadnienie wpływu warunków brzegowych i parametrów materiałowych na wyniki obliczeń. Zaprezentowano przykładowe wyniki oraz sposób ich interpretacji. Na podstawie wykonanych analiz oraz doświadczeń własnych autorów sformułowano wnioski końcowe.
\end{abstract}

Słowa kluczowe: budownictwo hydrotechniczne, modelowanie numeryczne, naziemny skaning laserowy, geofizyka

\footnotetext{
${ }^{1}$ Autor do korespondencji/corresponding author: Paweł Popielski, Politechnika Warszawska, Wydział Instalacji Budowlanych, Hydrotechniki i Inżynierii Środowiska, ul. Nowowiejska 20, 00653, Warszawa, pawel.popielski@is.pw.edu.pl

${ }^{2}$ Błażej Smoliński, Politechnika Warszawska, Wydział Instalacji Budowlanych, Hydrotechniki i Inżynierii Środowiska, ul. Nowowiejska 20, 00-653, Warszawa, blazej.smolinski@is.pw.edu.pl

${ }^{3}$ Adam Kasprzak, Politechnika Warszawska, Wydział Instalacji Budowlanych, Hydrotechniki i Inżynierii Środowiska, ul. Nowowiejska 20, 00-653, Warszawa, adam.kasprzak@is.pw.edu.pl
} 


\section{Wstęp}

Wielowariantowe obliczenia numeryczne stają się dzisiaj coraz popularniejszym narzędziem w praktyce inżynierskiej. Wspomagają proces projektowania oraz pozwalają na wczesną eliminację potencjalnych błędów konstrukcyjnych. Mogą być również wykorzystywane podczas eksploatacji już istniejących obiektów, w tym obiektów hydrotechnicznych. Z uwagi na rolę jaką pełnią tego typu konstrukcje $\mathrm{w}$ ochronie przeciwpowodziowej oraz $\mathrm{z}$ uwagi na potencjalne konsekwencje związane z ich awarią lub zniszczeniem, wymagają szczególnego nadzoru i regularnej oceny stanu technicznego. Zastosowanie do oceny stanu obiektów szeroko rozumianych technik modelowania numerycznego wydaje się być atrakcyjne pod kątem możliwości prowadzenia wielowariantowych i złożonych analiz. Zagadnieniem ściśle związanym z modelowaniem numerycznym, jest opracowanie programu badań pozwalających na zebranie dostatecznej ilości danych, niezbędnych do generacji modelu obliczeniowego. Oprócz danych dotyczących geometrii obiektu, konieczne jest również pozyskanie szeregu parametrów charakteryzujących właściwości materiałów z jakich wykonano konstrukcję. Konieczne są również informacje dotyczące budowy geologicznej podłoża. Obecnie rozwój techniki spowodował, że na rynku do dyspozycji mamy szereg metod badawczych, o różnym stopniu dokładności i zakresie pozyskiwania danych. Głównym ograniczeniem, z jakim spotykamy się w praktyce inżynierskiej jest zazwyczaj cena. Trzeba jednak pamiętać, że kwoty potrzebne na wykonanie niezbędnych badań stanowią zazwyczaj niewielki ułamek wartości całej inwestycji, nawet w przypadku technik powszechnie określanych mianem nowoczesnych. Jak pokazuje doświadczenie, wykonanie dokładnych i rzetelnych badań oraz zgromadzenie wszystkich niezbędnych danych przed przystąpieniem do realizacji projektu, pozwala uniknąć wielu komplikacji w dalszych etapach prac i analiz, także już po wykonaniu i w czasie eksploatacji obiektu.

\section{Interdyscyplinarne metody pozyskiwania danych}

Jednymi z coraz częściej i chętniej stosowanych w praktyce metod badawczych są metody geofizyczne (Rys. 1). Polegają na określeniu właściwości ośrodka przy użyciu takich parametrów jak oporność elektryczna, wartość stałej dielektrycznej oraz prędkość rozchodzenia się w nim fal sejsmicznych i elektromagnetycznych. Obecnie do najczęściej stosowanych należą metody sejsmiki powierzchniowej, metody elektrooporowe, a także metoda georadarowa [1] [4]. Pomiar wielkości fizycznych, charakterystycznych dla poszczególnych metod pozwala na określenie zróżnicowania poszczególnych stref ośrodka, ich zasięgu oraz występowania anomalii w jego budowie. Co ważne badania geofizyczne należą do grupy metod nieinwazyjnych i nieniszczących oraz są zalecane przez aktualne wytyczne do oceny stanu obiektów hydrotechnicznych [9]. Ich wykorzystanie nie wiąże się z bezpośrednią ingerencją $\mathrm{w}$ konstrukcję i nie powoduje 


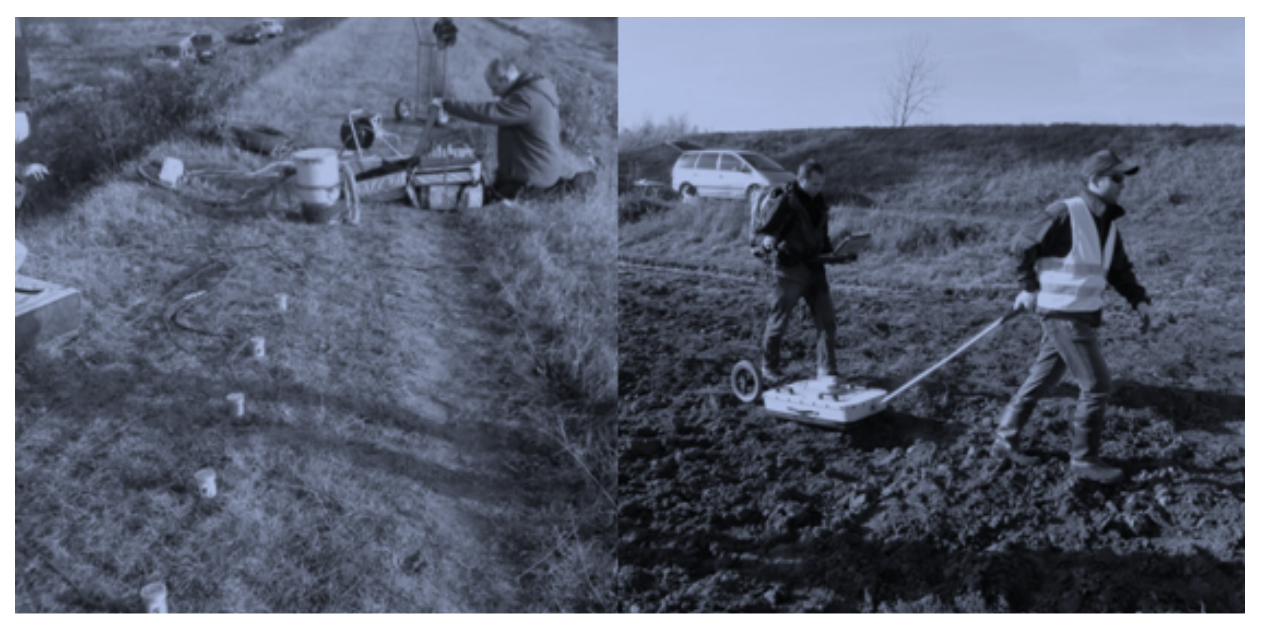

Rys. 1. Badania geofizyczne [1] [4]

Fig. 1. Geophysical tests [1] [4]

jej uszkodzenia czy degradacji [1] [4]. Ważną zaletą są również uzyskiwane dane pomiarowe o charakterze ciągłym, a nie punktowym. Należy jednak pamiętać o konieczności weryfikacji wyników uzyskiwanych metodami geofizycznymi. Wskazane jest jednoczesne stosowanie dwóch odmiennych technik badawczych oraz punktowe stosowanie tradycyjnych metod (np. odwiertów) w celu weryfikacji rezultatów badań geofizycznych. Weryfikacja powinna dotyczyć zarówno obszarów anomalii jak i tych, dla których nie wykryto zaburzeń. Pomimo tych niedogodności, przy stosowaniu metod geofizycznych, ciągłość pomiarów i zauważalnie mniejsza ingerencja w konstrukcje pozostaje kwestią niepodważalną.

Bardzo ciekawą technologią pozyskiwania danych do budowy modeli numerycznych jest skaning laserowy [6]. W wielu przypadkach umożliwia on automatyzację żmudnych i długotrwałych procedur pomiarowych. Stanowi ciekawą alternatywę dla niwelatorów, teodolitów i tachimetrów. Działanie skanera polega na generacji wiązki laserowej, która następnie ulega odbiciu od poszczególnych punktów pomiarowych znajdujących się w polu widzenia urządzenia. Dzięki georeferencji danych nadanej przez równoczesne zastosowaniu technologii pomiarów satelitarnych GNSS (Global Navigation Satellite System) oraz klasycznych pomiarów geodezyjnych [11], produktem końcowym jest chmura punktów o zdefiniowanych współrzędnych przestrzennych. Dane pozyskane z pomiaru skanerem laserowym dobrze odtwarzają rzeczywistą geometrię mierzonego obiektu. Uzyskana chmura punktów może stanowić podstawę do dalszych analiz, wykonywania modeli numerycznych, tworzenia animacji i wizualizacji. Przy pomocy odpowiedniego oprogramowania komputerowego, możliwa jest obróbka uzyskanych danych i generacja trójwymiarowego modelu 
obiektu. Stanowi to cenne źródło informacji przy konstrukcji obliczeniowych modeli numerycznych pozwalających na weryfikacje geometrii modelu. Szczególnego znaczenia nabiera to przy wykonaniu kilkukrotnych pomiarów w różnych odstępach czasu i możliwości wykorzystania różnicowych wyników przemieszczeń pomiędzy wykonanymi pomiarami [10].

W przypadku wykonanych pomiarów przemieszczeń i znanych zmian obciążenia obiektu w danym okresie eksploatacji, można oszacować parametry materiałowe. Podejście takie nosi nazwę tzw. ,,analizy wstecz”, a doświadczenia autorów pokazują, że wyznaczone w oparciu o nią wartości parametrów materiałowych dobrze odzwierciedlają stan faktyczny. Jest to jedna z możliwych dróg postępowania w przypadku braku wystarczającej ilości danych projektowych.

\section{Modelowanie numeryczne}

Analizy numeryczne konstrukcji można prowadzić rozmaitymi sposobami. Warto tu wspomnieć o metodzie różnic skończonych czy metodzie elementów brzegowych. Współcześnie jednym z najczęstszych stosowanych podejść jest wykorzystanie metody elementów skończonych (MES). Polega ona na dyskretyzacji analizowanego ośrodka na elementy skończone, dla których rozwiązywane są układy równań różniczkowych. Obliczenia prowadzone są wyłącznie w odniesieniu do węzłów podziału, a rozwiązanie jest przybliżane odpowiednimi funkcjami. Jakość uzyskiwanych wyników jest kwestią złożoną, zależną od poprawnie przyjętych scenariuszy obliczeniowych, prawidłowej budowy modelu i warunków brzegowych, czy w końcu rodzaju elementów skończonych i ilości węzłów. Oczywiście im większe zagęszczenie siatki, tym uzyskiwane wyniki są dokładniejsze. Wydłuża się jednak również czas prowadzenia takich obliczeń. Stąd częste próby korzystania z warunków symetrii, przekroi reprezentatywnych, bądź „sklejania” różnych siatek [8], co jest jednak zadaniem dość złożonym. Szerokie możliwości implementacji oraz duża efektywność powodują jednak, że w chwili obecnej MES jest wykorzystywana praktycznie we wszystkich dziedzinach nauki, z budownictwem hydrotechnicznym włącznie [7]. Z powodzeniem może być stosowana $\mathrm{w}$ analizach stanu naprężenia, odkształcenia, a także stateczności konstrukcji takich jak zapory ziemne i betonowe, mury oporowe, obwałowania przeciwpowodziowe.

Ważnym aspektem jest fakt, że MES umożliwia prowadzenie analiz uwzględniających współpracę obiektu z podłożem gruntowym, nawet w przypadku jego skomplikowanej budowy i złożonych warunków wodno-gruntowych. W takiej sytuacji otrzymane za pośrednictwem obliczeń numerycznych wyniki uzależnione będą w głównej mierze od przyjętych do analiz parametrów materiałowych oraz układu warstw litologicznych. W praktyce, kwestią niezwykle istotną jest dokładne rozpoznanie warunków wodno-gruntowych i poprawne wydzielenie stref materiałowych. Większość dostępnych na rynku pakietów obliczeniowych umożliwia różnicowanie wartości parametrów obliczeniowych 
w poszczególnych etapach prowadzonych analiz. Daje to duże możliwości w odwzorowaniu rzeczywistych warunków pracy konstrukcji, w tym uwzględnienie wpływu na wartości parametrów i zachowanie obiektu np. procesów konsolidacji, erozji czy sufozji.

Jak już wcześniej wspomniano zakres możliwych do prowadzenia analiz MES jest bardzo rozległy. Zagadnieniem istotnym w kontekście oceny stanu technicznego obiektów hydrotechnicznych jest ich stateczność. Obecnie pakiety MES (np. ZSoil) mają wbudowany moduł do obliczeń stateczności działający w oparciu metodę c- $\phi$ redukcji [8]. W jej wyniku, oprócz formy zniszczenia (bez ograniczania się do kołowej powierzchni poślizgu), określana jest także wartość współczynnika bezpieczeństwa. Jest to bardzo przydatne narzędzie, zwłaszcza w przypadku analizy pracy obwałowań przeciwpowodziowych w czasie wezbrania [5]. W przypadków oceny stateczności wałów przeciwpowodziowych należy stosować analizę filtracji nieustalonej, bazującej na aktualnym histogramie wezbrania, uwzględniającym zarówno wznoszenie jak i opadanie fali powodziowej. Na Rys. 2 pokazano wynik obliczeń stateczności przykładowego obwałowania z widoczną formą zniszczenia skarpy odpowietrznej przy napełnianiu się międzywala oraz skarpy odwodnej w czasie fazy opadania fali powodziowej.
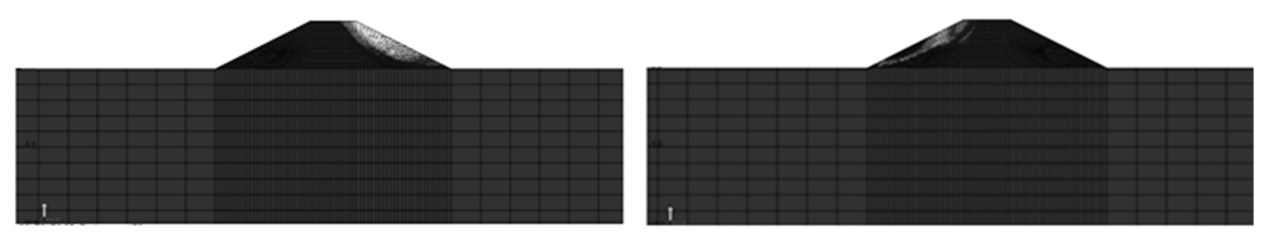

Rys. 2. Obliczenia stateczności wału przeciwpowodziowego. Formy zniszczenia [5]

Fig. 2. Stability calculations. A forms of destruction [5]

Zaprezentowane powyżej rezultaty obliczeń numerycznych dotyczą płaskich przekrojów 2D. Ich wykorzystanie jest możliwe przy braku istotnego zróżnicowania geometrii rozpatrywanego obiektu w przestrzeni. Należy jednak pamiętać również o zmienności parametrów materiałowych, w tym $\mathrm{z}$ reguły złożonej budowie geologicznej ośrodka gruntowego. W takich sytuacjach należy posłużyć się bardziej złożonymi modelami 3D. Pozwalają one na wierniejsze odzwierciedlenie rzeczywistych warunków pracy obiektu i analizę całości konstrukcji, w tym wytypowanie miejsc newralgicznych. Na Rys. 3 zaprezentowano model 3D fragmentu obwałowania przeciwpowodziowego, $\mathrm{z}$ widoczną strefą poślizgu w rejonie zakola [5].

Oprócz ziemnych obiektów hydrotechnicznych, takich jak zapory czy obwałowania, analizy numeryczne wykorzystywane są również przy ocenie konstrukcji betonowych [2]. Wiąże się to oczywiście z zastosowaniem innych modeli materiałowych i koniecznością wyznaczenia odpowiednich parametrów. 


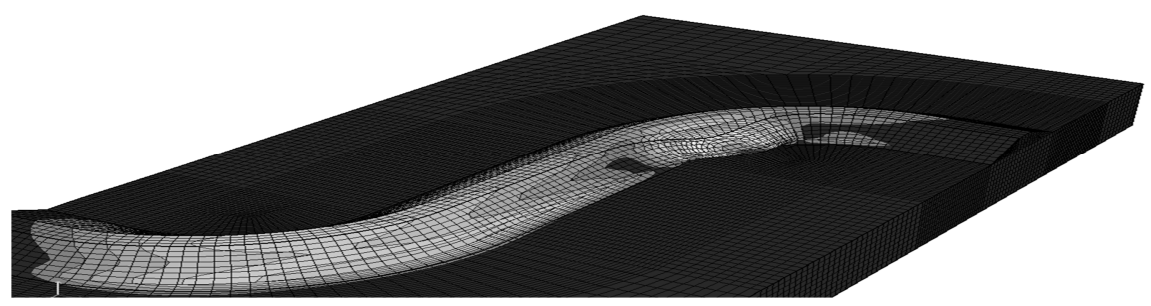

Rys. 3. Wał przeciwpowodziowy - model 3D. Widoczne miejsce awarii [5]

Fig. 3. Flood embankment - 3D model. Visible place of failure [5]

W analizach numerycznych dotyczących obiektow betonowych, konieczne jest uwzględnienie sezonowych zmian temperatury i związanych z tym naprężeń termicznych. Konieczne jest przy tym oddzielenie przemieszczeń wynikajacych ze zmian temperatury od przemieszczeń wynikajacych $\mathrm{z}$ innych oddziałwań. Jako przykład zaprezentowano model jednej sekcji zapory betonowej typu ciężkiego. Na Rys. 4 widoczne są uwzględnione przemieszczeniowe warunki brzegowe oraz jest odzwierciedlona skomplikowana struktura budowy podłoża skalnego. Dodatkowo zaprezentowano uzyskane wyniki obliczeń numerycznych w postaci przemieszczeń całkowitych dla analizowanej sekcji.
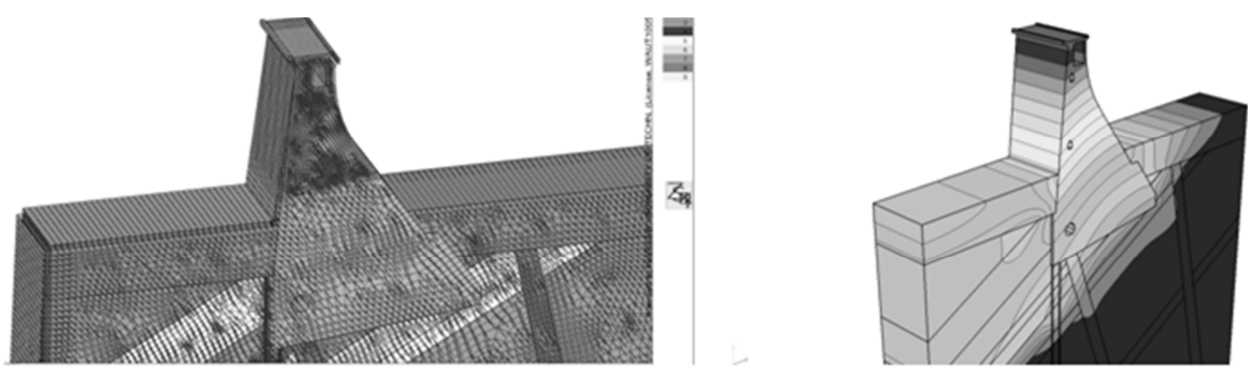

Rys. 4. Sekcja zapory betonowej - model 3D [2]

Fig. 4. Section of the concrete dam - 3D model [2]

\section{Podsumowanie i wnioski}

1. Generacja modelu numerycznego musi być poprzedzona starannym skompletowaniem niezbędnych danych dotyczących geometrii i parametrów materiałowych obiektu oraz podłoża gruntowego.

2. Wiarygodność wyników obliczeń numerycznych uzależniona jest od dokładności rozpoznania geologicznego i poprawności wyznaczania parametrów materiałowych. Niestandardowe metody obliczeń (modelownie numeryczne) wymuszają rozbudowę sieci monitoringu geodezyjnego i wykorzystanie nowoczesnych badań gruntu. 
3. Modelowanie numeryczne w odniesieniu do obiektów hydrotechnicznych umożliwia odzwierciedlenie złożonych warunków gruntowo-wodnych, co pozytywnie wpływa na jakość uzyskiwanych wyników oraz umożliwia przeprowadzenie wielowariantowych analiz i jest pomocne przy ocenie ich stanu technicznego.

4. Wydajność technik komputerowych i numerycznych metod obliczeniowych pozwala na generacje modeli 3D, w lepszy sposób odzwierciedlających rzeczywistą geometrię i warunki pracy analizowanych obiektu. Do tego celu, konieczne jest jednak posiadanie odpowiedniego zestawu danych dotyczących geometrii i parametrów materiałowych.

5. Wykonane obserwacje geodezyjne pozwalają zweryfikować poprawność modelu MES w stosunku do rzeczywistości. Konieczna jest weryfikacja danych pozyskanych interdyscyplinarnymi metodami badawczymi, w tym przy wykorzystaniu geofizycznych metod nieniszczących.

\section{Literatura}

[1] Barański M., Kłobukowski D., Makowski R., Popielski P., Smoliński B., Szczepański T.: Ocena stanu technicznego wałów przeciwpowodziowych z wykorzystaniem geofizycznych metod sejsmiki powierzchniowej. Monografia "Współczesne problemy inżynierii środowiska", Prace Naukowe. Inżynieria Środowiska, z. 70, Oficyna Wydawnicza Politechniki Warszawskiej, 2015.

[2] Bartnik E., Kasprzak A., Popielski P.: Wpływ temperatury i obciążenia wodą na przemieszczenia i naprężenia wybranych sekcji zapory betonowej w Rożnowie. Monografia ,, Eksploatacja budowli piętrzących-diagnostyka i zapobieganie zagrożeniom”, Winter Jan, Wita Andrzej, Instytut Meteorologii i Gospodarki Wodnej Państwowy Instytut Badawczy, Warszawa, 2015.

[3] Makowski R., Popielski P.: Wykorzystanie terenowych badań geofizycznych i modelowania numerycznego do oceny zmodyfikowanych wałów przeciwpowodziowych. Instytut Meteorologii i Gospodarki Wodnej Państwowy Instytut Badawczy, Warszawa, 2013.

[4] Popielski P., Kowalczyk S., Mieszkowski R., Chadaj M., Krysiak M., Smoliński B.: Ocena stanu technicznego wałów przeciwpowodziowych z wykorzystaniem metod geofizycznych i modelowania numerycznego. Monografia "Współczesne problemy inżynierii środowiska", Prace Naukowe. Inżynieria Środowiska, z. 70, Oficyna Wydawnicza Politechniki Warszawskiej, 2015.

[5] Popielski P., Smoliński B.: Wpływ geometrii obwałowań przeciwpowodziowych na ich stateczność. Monografia "Eksploatacja budowli piętrzących-diagnostyka i zapobieganie zagrożeniom", Winter Jan, Wita Andrzej, Instytut Meteorologii i Gospodarki Wodnej Państwowy Instytut Badawczy, Warszawa, 2015.

[6] Popielski P., Zaczek-Peplinska J.: Utilisation of terrestrial laser scanning for verification of geometry of numerical models of hydrotechnical structures using the example of a section of the concrete Besko Dam. Technical Transaction, Y. 110, iss. 1-Ś, Kraków, 2013.

[7] Popielski P., Zaczek-Peplinska J.: Wykorzystanie modeli numerycznych w eksploatacji budowli piętrzących. Gospodarka Wodna nr 2/2008, Warszawa. 
[8] Rodriguez C. \& Dendrou B., Zimmermann T.: Z_SOIL.PC: A program for solving soil mechanics problems on a personal computer using plasticity theory. Int. Conf. on Geomechanics, Innsbruck, Balkema, 1987.

[9] Sieinski E., Śliwiński P.: Wytyczne wykonania badań, pomiarów, ocen stanu technicznego i stanu bezpieczeństwa budowli piętrzących wodę. Instytut Meteorologii i Gospodarki Wodnej Państwowy Instytut Badawczy, Ośrodek Technicznej Kontroli Zapór, Warszawa-Katowice, 2015.

[10] Zaczek-Peplinska, J., Popielski, P., Kasprzak, A., Wójcik, P. (2014). Development of large concrete object geometrical model based on terrestrial laser scanning. Reports on Geodesy and Geoinformatics, 97, 91-102. http://doi.org/10.2478/rgg-2014-0014.

[11] Zaczek-Peplinska Janina, Kowalska Maria, Siejka Z.: Możliwości stosowania nowoczesnych metod pomiarowych do wyznaczania przemieszczeń i deformacji betonowych budowli piętrzących, w: Eksploatacja budowli piętrzących - diagnostyka i zapobieganie zagrożeniom / Winter Jan, Wita Andrzej, 2015, Instytut Meteorologii i Gospodarki Wodnej. Państwowy Instytut Badawczy, ISBN 978-83-64979-09-5, ss. 385-397.

\section{ASSESSMENT OF HYDRAULIC STRUCTURES BASED ON INTERDISCIPLINARY RESEARCH AND NUMERICAL SIMULATIONS}

\section{S u m m a r y}

The technical state of hydraulic objects plays an important role in the society and the national economy. These devices have important functions such as flood control, reservoir and recreation. Ensuring a proper technical state is very important for human security and many other economic aspects. Hence, an important issue is the possibility of a comprehensive analysis of this type of construction in terms of stress, displacement, filtration phenomena and stability. During analysis it is necessary to take into account the soil-structure-interaction. The work contains a few examples of numerical 2D and 3D models of different types of objects. The article presents the wide range of applications numerical analysis in the assessment of the technical state of hydraulic objects. The work focuses on modern methods of obtaining the data necessary for the generation of computational numerical models, with particular emphasis on non-destructive methods. In the article geophysical methods were briefly discussed. The theoretical basis of the finite elements method (FEM) is presented. The way of its implementation in the numerical analysis of hydraulic engineering constructions in relation to concrete and earthen objects was shown. Based on the analyzes and author's experience, the final conclusions were formulated.

Keywords: hydro-engineering, numerical modeling, laser scaning, geophysics

Przestano do redakcji: 07.06.2016 $r$.

Przyjęto do druku: $30.06 .2016 r$.

DOI: $10.7862 / \mathrm{rb} .2016 .57$ 